\title{
A Second Amelanistic Eastern Red-backed Salamander, Plethodon cinereus, from Nova Scotia, Canada
}

\author{
Ronald W. Russell ${ }^{1}$, Wilfried Beslin ${ }^{1}$, Maia Hudak ${ }^{1}$, Ayokunle Ogunbiyi ${ }^{1}$, Avery Withrow ${ }^{1}$, \\ and JOHN GILHEN ${ }^{2}$
}

${ }^{1}$ Department of Biology, Saint Mary's University, 923 Robie Street, Halifax, Nova Scotia, B3H 3C3 Canada; email: ron. russell@smu.ca

${ }^{2}$ Nova Scotia Museum of Natural History, 1747 Summer Street, Halifax, Nova Scotia B3H 3A6 Canada; email: gilhenja@ gov.ns.ca

Russell, Ronald W., Wilfried Beslin, Maia Hudak, Ayokunle Ogunbiyi, Avery Withrow, and John Gilhen. 2011. A second amelanistic Eastern Red-backed Salamander, Plethodon cinereus, from Nova Scotia, Canada. Canadian Field-Naturalist 125(4): 359-362.

In 2011, an amelanistic Eastern Red-backed Salamander, Plethodon cinereus, was discovered in Point Pleasant Park in Halifax, Nova Scotia. This is the second amelanistic Eastern Red-backed Salamander that has been documented from the Halifax area. Albino and leucistic individuals have also been identified from Nova Scotia. These aberrant conditions, including the two amelanistic individals, were discovered in isolated, fragmented, and disturbed habitat.

Key Words: amelanistic, Eastern Red-backed Salamander, Plethodon cinereus, anomaly, isolated, fragmented, disturbed, habitat, Point Pleasant Park, Halifax, Nova Scotia, Canada.

The Eastern Red-backed Salamander, Plethodon cinereus, is the most common and widespread salamander in Nova Scotia (Gilhen 1984). It is highly variable in colour and pattern throughout its range, and three morphs (redback, leadback, and erythristic or all red) are recognized in eastern North America. The redback and leadback colour morphs are common throughout Nova Scotia, however the third morph (erythristic) is known only from the deciduous forest of North Mountain (King's County), the Cobequid Mountains, and the Pictou highlands, all on the mainland. In Nova Scotia, the erythristic morph has been found only in association with the redback morph (Gilhen 1984).

Colour and pattern in all three morphs are plastic. Three anomalous conditions (albino, leucistic, and amelanistic) have been found in isolated, fragmented, and disturbed habitat in Nova Scotia (Moore and Gilhen 2011) (Figure 1). Leucistic salamanders are characterized by a general reduction in pigmentation, unlike albinism, where all pigmentation is absent. Amelanistic salamanders lack melanin but preserve other pigments, and thus retain more coloration than albino and leucistic anomalies. This note documents the observation of an amelanistic Plethodon cinereus in a highly disturbed forested site.

\section{Study Area}

Point Pleasant Park in Halifax, Halifax County, Nova Scotia, was formally established in 1866. Between 1749 and 1946, the park area was cleared repeatedly for agricultural and military purposes. It is a 77-ha fragment of Acadian forest in the south end of peninsular Halifax. It is highly disturbed, having suffered damage from the introduction of the Brown Spruce Longhorn Beetle (Tetropium fuscum) in 1998 (2000 trees were ultimately destroyed), from a severe ice storm in 2001 (during which 10000 trees were damaged), and from Hurri- cane Juan in 2003 (75\% of the park's forest-over 60000 trees - were toppled overnight) (Halifax Regional Municipality 2008*).

The forest at the site where the Eastern Red-backed Salamander was captured consists of a conifer and deciduous mix dominated by Red Maple (Acer rubrum), Red Oak (Quercus rubra), Eastern White Pine (Pinus strobus), and Eastern Hemlock (Tsuga canadensis). Other trees noted were standing and fallen Paper Birch (Betula papyrifera), Yellow Birch (Betula alleghaniensis), American Beech (Fagus grandifolia), White Spruce (Picea glauca), and Balsam Fir (Abies balsamea). Understory trees and shrubs include Speckled Alder (Alnus incana rugosa), Pin Cherry (Prunus pensylvanica), and Canada Yew (Taxus canadensis). Both Great Laurel (Rhododendron maximum) and English Oak (Quercus robur) were present in low numbers as exotic species.

The well-kept roads and paths are used extensively on a daily basis. Prior to Hurricane Juan, the forest was well manicured, and dead wood was removed. Since Hurricane Juan made landfall and passed through Point Pleasant Park, the numerous windfalls have been left under an open canopy to decay naturally on a thick bed of leaf and needle litter.

Point Pleasant Park is surrounded on three sides by marine waters and the city of Halifax to the north. There is a narrow strip of highly fragmented habitat on either side of a railway line that runs along the southwestern side of the city of Halifax. This railway comes within $300 \mathrm{~m}$ of the park at its nearest approach.

\section{Methods}

Limited surveys for the Eastern Red-backed Salamander have been conducted, mostly by university students, in Point Pleasant Park since 2003 (< 100 captures per year). On 18 October 2011, four students from 


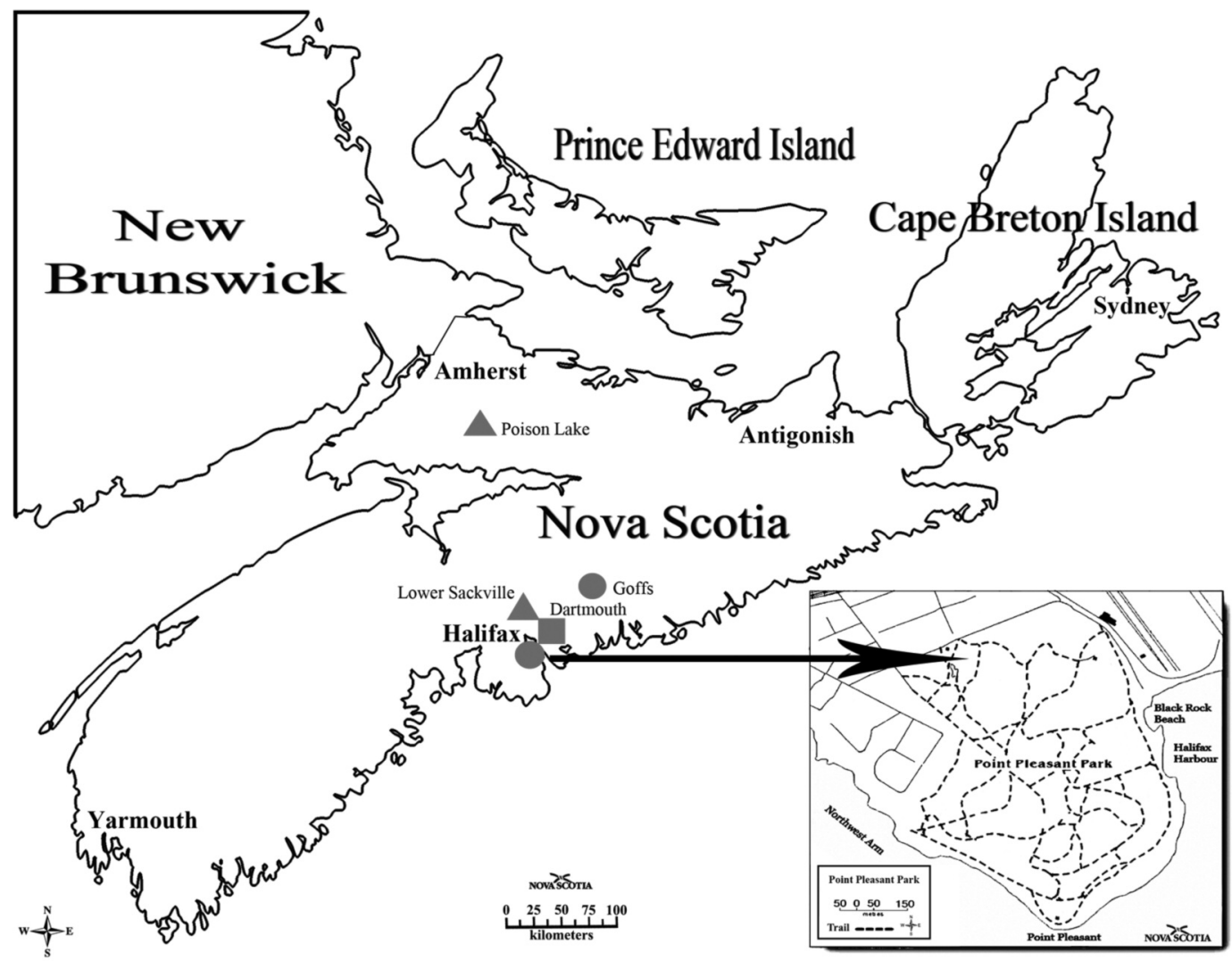

FIGURE 1. Distribution of three aberrant forms of the Eastern Red-backed Salamander, Plethodon cinereus, in Nova Scotia. The square represents one albino from near the Dartmouth side of the Angus L. Macdonald Bridge; triangles represent leucistic individuals, one from Lower Sackville and one from the Poison Lake area (Gilhen, unpublished data); circles represent amelanistic individuals, one from the Goffs area (Moore and Gilhen, 2011) and one from Point Pleasant Park, Halifax.

Saint Mary's University (W. B., M. H., A. O., and A. W.) were collecting Eastern Red-backed Salamanders by turning over rocks and coniferous and deciduous logs in the park $\left(44^{\prime} 37.564^{\prime \prime} \mathrm{N}, 63^{\prime} 34.390^{\prime \prime} \mathrm{W}\right)$.

The amelanistic salamander collected on 18 October 2011 was measured with a digitial caliper.

\section{Results and Discussion}

Eastern Red-backed Salamanders thrive under the cover of fallen logs and rocks on deep leaf and needle litter in this isolated and disturbed habitat (Figure 2). A total of 20 Plethodon cinereus (12 redback, 7 leadback, and 1 amelanistic) were captured in fall 2011. The amelanistic individual collected on 18 October 2011 (Figure 3) was young, measuring $15.0 \mathrm{~mm}$ body length and $24.31 \mathrm{~mm}$ total length. The head, trunk, and tail were white, with a brief peach-red or peachyellow (depending on light and magnification) stripe on the back and across the front of the snout. The iris was white and the pupil was grey. The underside of the abdomen (Figure 4) was translucent white, and the red pumping heart was visible in the live specimen. It was placed in the Nova Scotia Museum of Natural History Amphibian Collection (catalogue number NSM 55572).

Of 48 Plethodon cinereus captured between October and December 2010 in Point Pleasant Park, 29 were redback individuals. Since 2003, the redback morph has constituted $61 \%$ and the leadback $39 \%$ of captures in Point Pleasant Park, and only the one amelanistic salamander (collected in 2011) has been observed.

The amelanistic Eastern Red-backed Salamander described in this note was clearly a juvenile, and anomalous individuals like this one may not survive to reproduce. Moore and Gilhen (2011) reported an adult amelanistic $P$. cinereus observed adjacent to a clear-cut in Nova Scotia. This second observation of an amelanistic salamander in Nova Scotia (in an area that had been devastated by Hurricane Juan) could indicate an advantage of this colour anomaly in highly disturbed habitats or it could be a consequence of genetic drift 


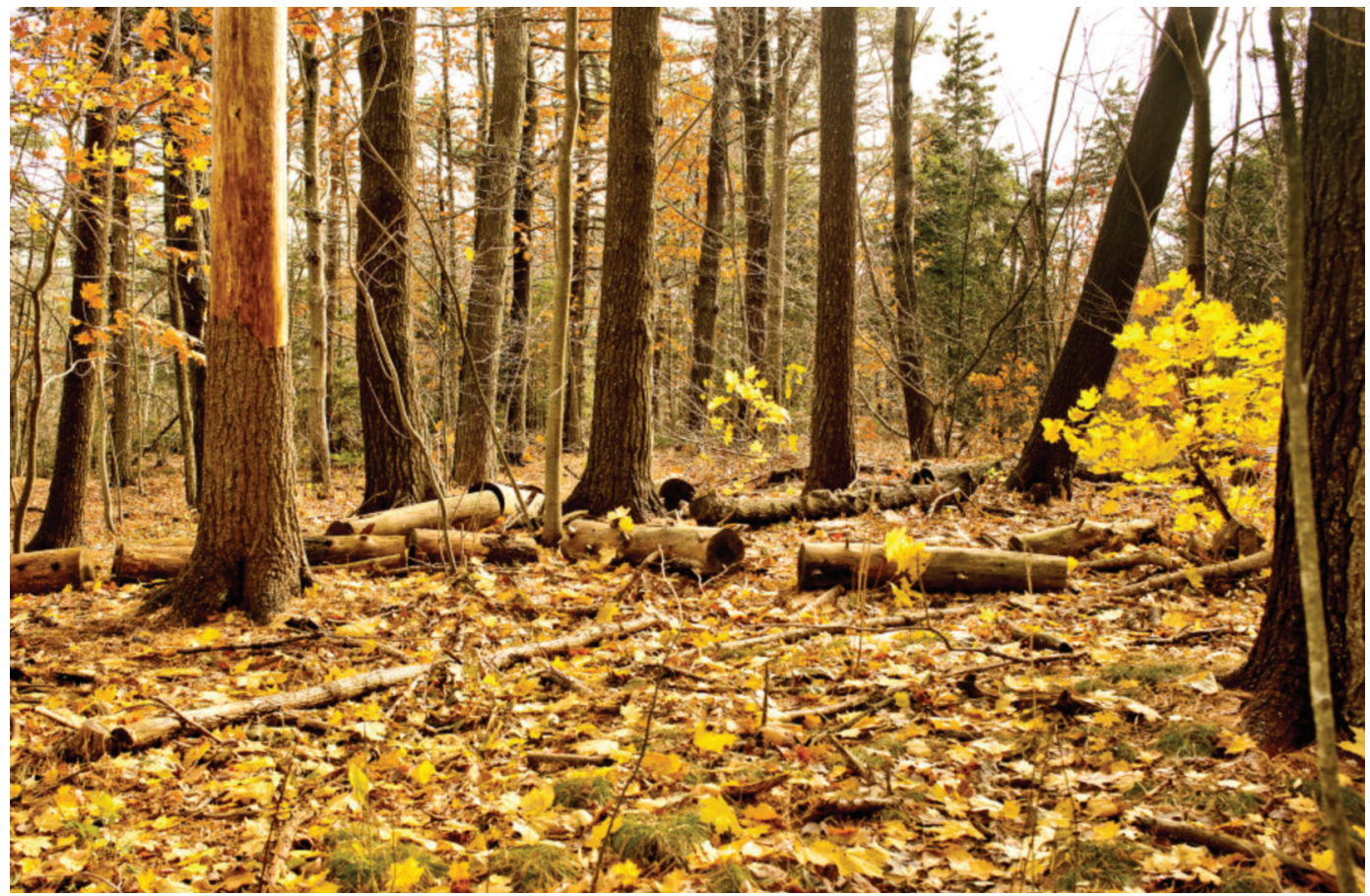

FIgURE 2. Habitat where a variant of the amelanistic condition of the Eastern Red-backed Salamander, Plethodon cinereus, was discovered in Point Pleasant Park, Halifax, Nova Scotia. Photo: Roger Lloyd, Nova Scotia Department of Communities, Culture, and Heritage.

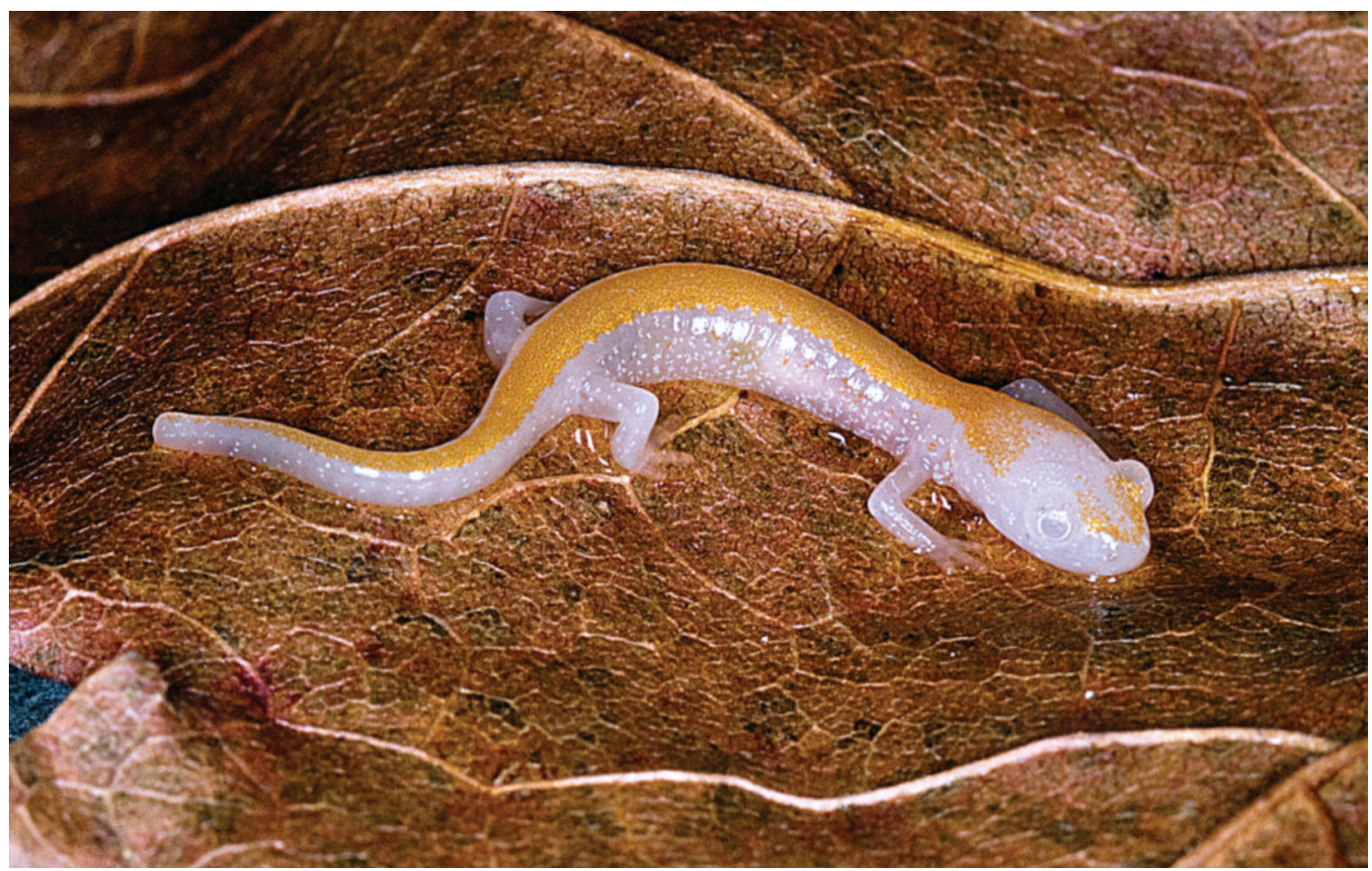

FIGURE 3. Dorsal-lateral view of a variant of the amelanistic condition of the Eastern Red-backed Salamander, Plethodon cinereus, from Point Pleasant Park, Halifax, Nova Scotia. Photo: Roger Lloyd, Nova Scotia Department of Communities, Culture, and Heritage. 


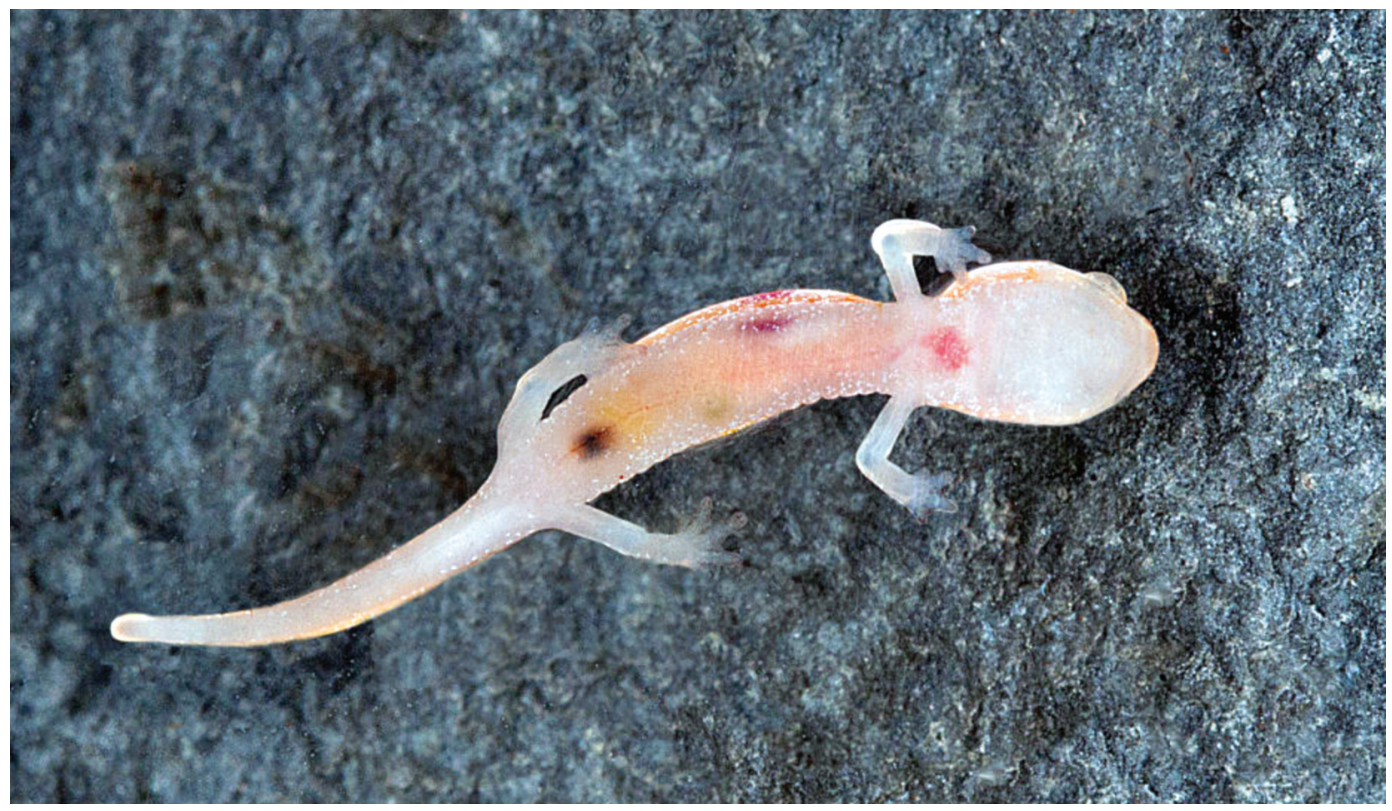

FIGURE 4. Ventral view of a variant of the amelanistic condition of the Eastern Red-backed Salamander, Plethodon cinereus, from Point Pleasant Park, Halifax, Nova Scotia. Photo: Roger Lloyd, Nova Scotia Department of Communities, Culture, and Heritage.

in a small, isolated population. This could also be a chance observation of a rare event.

Maintenance of colour polymorphism in $P$. cinereus is attributed to differential physiology and behaviour leading to increased predation on the unstriped leadback morph (Moreno 1989; Venesky and Anthony 2007). Because Eastern Red-backed Salamanders have small territories $\left(0.16-0.33 \mathrm{~m}^{2}\right)$ (Petranka 1998) and disperse less than $2 \mathrm{~m}$ per year (Ousterhout and Liebgold 2010), it is likely that the population of Eastern Red-backed Salamanders in Point Pleasant Park is spatially and genetically isolated from nearby populations. The nearest documented population of Eastern Red-backed Salamanders is approximately $650 \mathrm{~m}$ away from the capture location, on the southern extent of the campus of Saint Mary's University adjacent to the railway line. Other populations exist on McNabs Island (1800 $\mathrm{m}$ distant) and Williams Lake (565 m distant), both across marine waters.

In this era of global climate change and extensive habitat modification and fragmentation, anomalous conditions such as amelanism may increase in populations. This note constitutes a call for documentation of observations of such anomalous salamanders.

\section{Acknowledgements}

Photography was by Roger Lloyd, Nova Scotia Department of Communities, Culture, and Heritage. Eastern Red-backed Salamanders were collected under a Nova Scotia Department of Natural Resources permit to R. Russell and an animal care protocol from the
Saint Mary's University/Mount Saint Vincent University Animal Care Committee (11-24E-R). Students (W. Beslin, M. Hudak, A. Ogunbiyi, A. Withrow) were supervised by Colleen Barber.

Documents Cited (marked * in text)

Halifax Regional Municipality. 2008. Point Pleasant Park Comprehensive Plan. Halifax Regional Municipality, Halifax, Nova Scotia. 304 pages.

\section{Literature Cited}

Gilhen, J. 1984. Amphibians and Reptiles of Nova Scotia. Nova Scotia Museum, Halifax, Nova Scotia. 162 pages.

Moore, J-D., and J. Gilhen. 2011. Two amelanistic Eastern Red-backed Salamanders (Plethodon cinereus) from eastern Canada. Canadian Field-Naturalist 125: 58-60.

Moreno, G. 1989. Behavioral and physiological differentiation between the color morphs of the salamander Plethodon cinereus. Journal of Herpetology 23: 335-341.

Ousterhout, B. H., and E. B. Liebgold. 2010. Limited dispersal and site tenacity of adult and juvenile Red-Backed Salamanders (Plethodon cinereus). Herpetologica 66: 269275.

Petranka, J. W. 1998. Salamanders of the United States and Canada. Smithsonian Institution Press, Washington, D.C. 576 pages.

Venesky, M. D., and C. D. Anthony. 2007. Antipredator adaptations and predator avoidance by two color morphs of the eastern red-backed salamander Plethodon cinereus. Herpetologica 63: 450-458.

Received 17 January 2012

Accepted 8 February 2012 